them into water or molecular hydrogen, and thus suppresses to a certain extent the production of current.

A photosensitized decomposition of water could well account for experimental results published by other authors on photovoltaic phenomena in aqueous solutions $^{1-3}$ as well as on the acceleration of electrodeposition of hydrogen and oxygen by ultra-violet light ${ }^{4-6}$.

Polarographic Institute,

M. HEYRovskÝ

Czechoslovak Academy of Sciences, Prague, and University of Cambridge.

R. G. W. NorRIsH

Department of Physical Chemistry,

University of Cambridge.

${ }^{2}$ Swensson, T., Arkiv Kemi, Min. och Geologi, 7, No. 19, 1 (1919).

Lifschitz, J., and Hooghoudt, S. B., Z. phys. Chem., A, 141, 52 (1929).

${ }^{3}$ Audubert, R., J. Chim. Phys., 27, 169 (1930).

4 Bowden, F. P., Trans. Farad. Soc., 27, 505 (1931).

s Price, L. E., Dissertation, Cambridge Univ. (1938).

${ }^{6}$ Hillson, P. J., and Rideal, E. K., Proc. Roy. Soc., A, 199, 295 (1949).

\section{Effect of Geometrical Isomerism on the Behaviour of cis and trans Hexahydroindanes under Electron Impact}

RecentLY ${ }^{1}$ I reported observations on the behaviour of cis and trans decalines under electron impact. It was shown that in these ionized stereoisomers an effect due to geometrical isomerism appears in two different ways. First, mass spectra, although qualitatively identical, show important differences between relative abundances of several main fragment ions. Relative abundances of molecular ions also differ and indicate a greater stability of ionized trans isomer. Secondly, from the point of view of energetics two results were obtained: $(a)$ Ionization potentials measured for both isomers are the same, $9 \cdot 61 \pm 0.02 \mathrm{eV}$, within experimental uncertainties. $(b)$ Appearance potentials of the two fragment ions first produced indicate that a lower energy is required to dissociate ionized cis isomer into fragments.

All these results can be interpreted in a satisfactory manner if it is noticed that the greater stability of ionized trans isomer parallels its greater thermodynamic stability which represents about $3 \mathrm{kcal} / \mathrm{mole}$ (ref. 2). An amount of energy of that order due to steric conformation is released in cis decaline when fragmentation occurs.

I wondered if a similar behaviour could still be observed in a case where the difference of thermodynamic stability between cis and trans isomers is smaller-the cis and trans hexahydroindanes (bicyclo-0,3,4-nonanes). Thermodynamic stability of cis isomer is only $1 \mathrm{kcal} / \mathrm{mole}$ smaller than that of trans isomer ${ }^{3}$.

Similar experiments were performed on hexahydroindanes as on decalines. (a) Mass spectra were recorded for electron energies of a few volts above ionization potential, and relative abundances expressed as a fraction of total ionic current were calculated. (b) Ionization potentials of both isomers were determined as well as appearance potentials of the two main fragment ions, that is, $\mathrm{C}_{7} \mathrm{H}_{32}{ }^{+}$and $\mathrm{C}_{6} \mathrm{H}_{10}{ }^{+}$, mass numbers 96 and 82 , which are formed in the simplest way as shown in the following scheme:

and

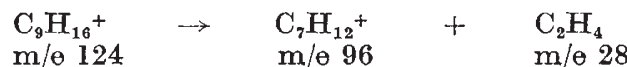

m/e 124

$\begin{aligned} & \mathrm{C}_{9} \mathrm{H}_{16}{ }^{+} \\ & \mathrm{m} / \mathrm{e} 124\end{aligned} \rightarrow \underset{\mathrm{m} / \mathrm{e} 82}{\mathrm{C}_{6} \mathrm{H}_{10}{ }^{+}}+\underset{\mathrm{m} / \Theta 42}{\mathrm{C}_{3} \mathrm{H}_{6}}$

Appearance potentials of three other important frag. ment ions, $\mathrm{C}_{7} \mathrm{H}_{11}{ }^{+}, \mathrm{C}_{6} \mathrm{H}_{9}{ }^{+}$and $\mathrm{C}_{5} \mathrm{H}_{7}+$, absent in mass spectra at 10 volts but present at 12 volts, have also been determined.

Relative abundances of ions are given in Table $\mathbf{l}$ for 12 and 10 volts electron energies.
Table 1. MASS SPECTRA OF cis AND trans HEXAHYDROINDANES AT 12 AND $10 \mathrm{~V}$ (PERCENTAGE OF TOTAL IONIC CURRENT)

\begin{tabular}{|c|c|c|c|c|c|c|c|}
\hline Ion formula & $\mathrm{C}_{9} \mathrm{H}_{18}{ }^{+}$ & $\mathrm{C}_{7} \mathrm{H}_{18}+$ & $\mathrm{C}_{7} \mathrm{H}_{11}{ }^{+}$ & $\mathrm{C}_{6} \mathrm{H}_{10}+$ & $\mathrm{C}_{6} \mathrm{H}_{8}+$ & $\mathrm{C}_{5} \mathrm{H}_{8}+$ & $\mathrm{C}_{5} \mathrm{H}_{7}+$ \\
\hline Mass No. & 124 & 96 & 95 & 82 & 81 & 68 & 67 \\
\hline $\begin{array}{l}\text { cis isomer } \\
\text { trans isomer } \\
10 \mathrm{~V}\end{array}$ & $\begin{array}{l}19 \cdot 9 \\
28 \cdot 5\end{array}$ & $\begin{array}{l}31 \cdot 3 \\
26 \cdot 3\end{array}$ & $\begin{array}{l}2 \cdot 3 \\
3 \cdot 3\end{array}$ & $\begin{array}{l}26 \cdot 1 \\
22 \cdot 3\end{array}$ & $\begin{array}{l}8 \cdot 5 \\
3 \cdot 7\end{array}$ & $\begin{array}{l}1 \cdot 0 \\
1 \cdot 3\end{array}$ & $\begin{array}{l}2 \cdot 5 \\
6 \cdot 1\end{array}$ \\
\hline $\begin{array}{l}\text { cis isomer } \\
\text { trans isomer }\end{array}$ & $\begin{array}{l}48 \cdot 7 \\
62 \cdot 2\end{array}$ & $\begin{array}{l}23 \cdot 1 \\
17 \cdot 9\end{array}$ & 二 & $\begin{array}{l}28 \cdot 2 \\
20 \cdot 0\end{array}$ & 二 & $\overline{-}$ & 二 \\
\hline
\end{tabular}

The figures in Table 1 show important differences between relative abundances of molecular ions and main fragment ions in cis and trans hexahydroindanes and indicate a greater stability of trans isomer as in the case of decalines.

Table 2 gives results obtained for ionization potentials $(I P)$ and appearance potentials $(A P)$ in the two isomers under the same experimental conditions as for decalines. Ionization efficiency curves have been treated by Warren's method 4 .

Table 2. IONIZATION Potrentuls of cig axp trans HexaHyDRorndares and Appearance potentlals of Main Fragment Ions (eV)

\begin{tabular}{|c|c|c|c|}
\hline \multicolumn{2}{|c|}{$\begin{array}{l}\text { Formula and mass } \\
\text { No. of the ion }\end{array}$} & cis isomer & trans isomer \\
\hline $\begin{array}{l}I P\left(\mathrm{C}_{9} \mathrm{H}_{18}{ }^{+}\right) \\
A P\left(\mathrm{C}_{7} \mathrm{H}_{18}^{+}\right. \\
A P\left(\mathrm{C}_{7} \mathrm{H}_{11^{+}}\right) \\
A P\left(\mathrm{C}_{6} \mathrm{H}_{10}^{+}\right) \\
A P\left(\mathrm{C}_{6} \mathrm{H}_{6}^{+}\right) \\
A P\left(\mathrm{C}_{5} \mathrm{H}_{7}^{+}\right)\end{array}$ & $\begin{array}{r}124 \\
96 \\
95 \\
82 \\
81 \\
67\end{array}$ & $\begin{array}{l}10.13 \pm 0.03 \\
10.96 \pm 0.03 \\
11.71 \pm 0.05 \\
10.79 \pm 0.03 \\
11.99 \pm 0.05 \\
12.21 \pm 0.05\end{array}$ & $\begin{array}{l}10.18 \pm 0.03 \\
11.16 \pm 0.03 \\
11.80 \pm 0.05 \\
11.00 \pm 0.02 \\
12.07 \pm 0.04 \\
1219 \pm 0.03\end{array}$ \\
\hline
\end{tabular}

From these results it turns out that, within experimental error, ionization potentials of cis and trans hexahydroindanes are the same. On the other hand, appearance potentials of the two principal fragment ions, $\mathrm{C}_{7} \mathrm{H}_{11}{ }^{+}$ and $\mathrm{C}_{6} \mathrm{H}_{10}{ }^{+}$, are different, the values boing smaller for the cis isomer than for the trans isomer. For the other fragment ions investigated, no difference between appearance potentials could be detected.

As a consequence, the behaviour of cis and trans hexahydroindanes under electron impact appears quite similar to that found in cis and trans decalines. Although the difference between thermodynamic stabilities is very small in this case, only about $0.05 \mathrm{eV}$, there is a noticeable difference between the stabilities of ionized molecules as well as in the energetics of further decomposition of both isomers.

The results recorded here can be interpreted in the following way. (a) Relative thermodynamic stabilities are reflected in the behaviour of ionized isomers in the fundamental state. (b) An amount of energy of I kcal/ mole provided by steric conformation is released in cis isomer when the molecule breaks down into masses 96 and 82 , and used in the breaking process itself.

Similar cases of more complex systems are being investigated in this laboratory. I thank Prof. L. D'Or and the Fonds National de la Recherche Scientifique for advice and support.

P. Natalis

Faculty of Sciences,

University of Liège, Belgium.

${ }^{1}$ Natalis, P., Nature, 197, 284 (1963).

${ }^{2}$ Speros, D. M., and Rossini, F. D., J. Phys. Chem., 64, 1723 (1960).

3 Browne, C. C., and Rossini, F. D., J. Phys. Chem., 64, 927 (1960).

" Warren, J. W., Nature, 165, 811 (1950).

\section{Hydrolysis of the Phosphorothioate Ion catalysed by Silicone Grease}

WHEN preparing trisodium phosphorothioate from thiophosphoryl chloride and sodium hydroxide at $80^{\circ}$ according to Alkerfeldt'1 it was observed that the yields became much smaller when the ground-glass joints of the apparatus used had been treated with silicone grease. In fact, in some cases no trisodium phosphorothioate could be isolated from the reaction mixture. In these instances liberal amounts of silicone grease had been used in lubricating the glass joints.

Thus it was observed that silicone grease in some way interfered with the reaction between thiophosphoryl 